\title{
Suplementação de fêmeas bovinas em pastejo: aspectos nutricionais e reprodutivos
}

Moacir Ferreira Duarte Júnior ${ }^{1}$, Luciana Keiko Hatamoto Zervoudakis ${ }^{1,2}$, Joanis Tilemahos Zervoudakis $^{1,3}$, Pedro Paulo Tsuneda ${ }^{1}$, Joelson Antônio Silva ${ }^{1}$, Renata Pereira da Silva ${ }^{1}$, Jefferson Fabiano Werner Koscheck ${ }^{4}$, Ricardo Sergio Fioravanti Filho ${ }^{5}$, Rodrigo Delbem Almeida ${ }^{6}$.

\author{
${ }^{1}$ Programa de Pós Graduação em Ciência Animal , FAMEVZ, UFMT; Cuiabá-MT, Brasil \\ ${ }^{2}$ Dept. Clinica Médica Veterinária (CLIMEV), FAMEVZ, UFMT; Cuiabá-MT, Brasil \\ ${ }^{3}$ Dept. Ciências Básicas e Produção Animal (DCBPA), FAMEVZ, UFMT; Cuiabá-MT, Brasil \\ ${ }^{4}$ Programa de Pós Graduação em Zootecnia, UNESP, Jaboticabal-SP, Brasil. \\ ${ }^{5}$ Zootecnista autônomo. Cuiabá-MT, Brasil \\ ${ }^{6}$ Aluno de graduação em Medicina Veterinária, FAMEVZ, UFMT; Cuiabá-MT, Brasil \\ *Autor para correspondencia, E-mail: joelson.silva@hotmail.com
}

\begin{abstract}
RESUMO. O Brasil possui uma cadeia produtiva de bovinos baseada na produção a pasto, o que a torna de baixo custo, porém com uma baixa margem de lucro. Por isso tem passado por uma série de mudanças devida a competição com outras cadeias produtivas de proteína animal, como, suínos e aves e também com a agricultura que avança rapidamente em áreas que até então eram ocupadas para exploração pecuária. Dessa forma com um cenário de rentabilidade baixa e alta competição é preciso buscar alternativas que permita sua sobrevivência e lucratividade. Mesmo com o maior rebanho comercial do mundo, a pecuária brasileira apresenta índices zootécnicos abaixo do real potencial, principalmente pela baixa eficiência reprodutiva das fêmeas do rebanho. Para que a atividade se torne sustentável é importante a inserção de tecnologias que permitam explorar ao máximo a capacidade produtiva desses animais. Recentemente muito tem se estudado a respeito de suplementação de fêmeas em pastejo, que se mostra como uma alternativa indispensável seja na fase de cria ou recria visto que a ingestão adequada de nutrientes é fundamental para o desenvolvimento reprodutivo nos bovinos. O sistema de manejo extensivo do Zebu que é utilizado na maioria das propriedades no Brasil é a principal causa de puberdade tardia desses animais, que irá interferir na idade que entraram em estação de monta e idade ao primeiro parto. Também durante a gestação o aporte nutricional adequado é de suma importância, evidências demonstram que o desenvolvimento do músculo esquelético e deposição de tecido adiposo do feto podem ser alterados em casos de subnutrição, com efeitos em longo prazo sobre seu desempenho na vida adulta. Objetivou-se com este trabalho destacar alguns aspectos que comprovam a influência da nutrição na fisiologia reprodutiva de fêmeas em pastejo recebendo suplementação.
\end{abstract}

Palavras chave: Eficiência reprodutiva, fêmeas zebuínas, precocidade, programação fetal, puberdade

\section{Supplementation of bovine females in grazing: Nutritional and reproductive aspects}

\begin{abstract}
Brazil has a cattle production chain based on grazing production, which makes it inexpensive, but with a low profit margin. For that reason, it has gone through a series of changes due to competition with other animal protein production chains, such as pigs and poultry and also with the agriculture, which rapidly moves into areas that were previously occupied for the livestock farming. Thus, with a scenario of low profitability and high competition, it is necessary to find alternatives that allow its survival and profitability. Even with the largest commercial herd in the world, Brazilian livestock presents levels below its true potential, especially due to the low reproductive efficiency of the females of the herd. So that the activity becomes sustainable, it is important the inclusion of technologies to make use of the maximum productive capacity of these animals. Recently, many studies have been done regarding the supplementation of
\end{abstract}


grazing females, and it presents itself as an essential alternative in both the birth or rearing processes, in view of the fact that the adequate intake of nutrients is essential for reproductive development in cattle. The Zebu extensive management system, which is used in most of the cattle farms in Brazil, is the main cause of the delayed puberty of these animals, which will interfere in the age they went into the breeding season and the age of the first calving. Also during pregnancy the proper nutritional support is extremely important, evidence shows that the development of the skeletal muscle and deposition of adipose tissue of the fetus may be altered in cases of malnutrition, with long-term effects on their performance in adulthood. This study aimed at pointing out some aspects that confirm the influence of nutrition on reproductive physiology of grazing females receiving supplementation.

Key words: Reproductive efficiency, Bos indicus females, precocity, fetal programming, puberty

\section{Introdução}

A produtividade e eficiência reprodutiva de vacas de corte em pastejo dependem de uma série de fatores. Condições de baixa qualidade e produtividade das pastagens associadas a uma não suplementação de minerais e nutrientes limitantes (proteína e energia), levam a baixos índices de eficiência reprodutiva do rebanho, como, baixa taxa de concepção, alta mortalidade embrionária, problemas de parto, mortalidade de bezerros, baixas taxas de crescimento pós natal entre outras (Pires et al., 2011).

A melhoria da eficiência reprodutiva dentro do sistema de produção bovino deve ser uma das metas quando se busca maior produtividade e rentabilidade. O desempenho reprodutivo é o principal fator limitante na produção de bovinos de corte (Ferreira, 1992) e está diretamente relacionado com o período de serviço e com o intervalo entre partos, uma vez que sua ampliação diminui o número de crias durante a vida reprodutiva da matriz (Borgeset al., 2009). Sendo que o período de serviço é uma característica influenciada principalmente pelas condições ambientais e nutricionais que se encontra o animal, sendo considerada de herdabilidade baixa ou próxima de zero (Freitas et al., 1997).

Mesmo possuindo o maior rebanho comercial do mundo, com cerca de 200 milhões de cabeças, a pecuária de corte brasileira ainda apresenta índices zootécnicos abaixo do potencial que pode alcançar, principalmente pela baixa performance reprodutiva das fêmeas (Parra \& Beltran, 2008) que representam cerca de $31 \%$ desse total, dessa forma a importância do setor de cria não pode ser subestimado dentro da eficiência de produção de bovinos de corte (Calegare, 2004).
Segundo Amaral et al. (2005) a taxa de natalidade do rebanho bovino brasileiro encontrase em torno de $60 \%$, enquanto em países com um certo nível de tecnificação na pecuária tem em média cerca de $80 \%$. Isso se deve em parte pelo fato de mais de $90 \%$ do rebanho do Brasil ser criado a pasto, muitas vezes de forma extensiva cuja cerca de $70 \%$ das pastagens estão em algum estágio de degradação. Outro fator negativo se deve as melhores pastagens na maioria das vezes serem destinadas às categorias de recria e engorda, quando deveriam ser destinadas também a novilhas pré-púberes e fêmeas gestantes, principalmente aquelas com condição corporal deficiente. Visto que, melhorando a eficiência reprodutiva e aumentando o número de bezerros nascidos, leva a diminuição do tempo ocioso das matrizes que é responsável pelo produto da fazenda, o boi gordo destinado ao abate futuramente (Oliveira et al., 2006).

Zanine et al. (2011), destacaram justamente o fato da base de criação do nosso rebanho em sistemas de pastejo aliado à nossa vasta extensão territorial e a colheita da forragem pelo próprio animal, como um fator determinante na redução de custos com alimentação dentro do custo de produção, colocando a produção de carne bovina do Brasil competitiva frente a outros sistemas de produção, alcançando destaque no cenário internacional, como um dos maiores exportadores de carne bovina do mundo. Dessa forma é preciso aliar esse grande potencial à introdução de novos conceitos no que diz respeito a manejo de pastagens, ajustes na taxa de lotação e uso de alimentos suplementares de forma estratégica como volumosos (forragens conservadas, diferimento de pastagem) ou concentrados (protéicos ou energéticos). 
Santos \& Sá Filho (2006) destacaram a ingestão adequada de nutrientes como fundamental para o desempenho reprodutivo de bovinos, que irá influenciar no eixo hipotálamohipófise-gonadal (eixo reprodutivo) modificando o padrão de crescimento folicular, atividade lútea e atividade secretória do útero. Em conjunto, esses fatores irão diretamente e indiretamente determinar a idade à maturidade, aparecimento da puberdade retorna a ciclicidade pós-parto, concepção e manutenção da gestação.

Estudos realizados por Cooke (2011) demonstrou a importância de um estado nutricional adequado em fêmeas de cria, seja novilhas de reposição ou fêmeas multíparas. Também destacou a importância do aporte nutricional para fêmeas gestantes em todas as fases de desenvolvimento fetal, visto afetar posteriormente a produtividade do bezerro do nascimento ao abate. Dessa forma a manutenção do rebanho de cria ao longo do ano proporcionando níveis nutricionais adequados é indispensável em sistemas de pecuária moderna eficiente.

Du et al. (2010) apontam evidências demonstrando o nível de nutrição materna durante a gestação interferindo no desenvolvimento muscular esquelético fetal, com efeitos a longo prazo sobre o desenvolvimento pós-natal. Dessa forma é possível adotar estratégias conhecidas como "programação fetal", identificando e suprindo os nutrientes limitantes, no intuito de melhorar o crescimento muscular e marmoreio na prole.

Ingestão adequada de nutrientes é de suma importância na regulação da reprodução em ruminantes, podendo ser considerado fator determinante na expressão do potencial genético dos animais (Maggioni et al., 2008).

O objetivo desta revisão é destacar alguns aspectos relevantes que comprovam a influência da nutrição na fisiologia da reprodução de fêmeas em pastejo recebendo suplementação.

\section{Precocidade reprodutiva e manejo de novilhas}

Do rebanho total brasileiro cerca de $8 \%$ são novilhas com idade entre dois e três anos totalizando aproximadamente 16 milhões de cabeças (ANUALPEC, 2010). Como a eficiência econômica da pecuária de corte é dependente da produção de bezerros tanto para abate como para fêmeas de reposição, a eficiência reprodutiva em novilhas se torna de grande importância, buscando reduzir a idade à puberdade que é a primeira ovulação fértil acompanhada de uma fase luteal de duração normal e antecipando a idade ao primeiro parto (Sá Filho et al., 2008).

Aumentos na frequiência de pulsos de LH é o pré requisito para a puberdade, momentos que antecedem a primeira ovulação são acompanhados de diminuição de feedback negativo do estradiol sobre o hipotálamo, promovendo maior produção e liberação de GnRH que atua na hipófise aumentando a produção e liberação de $\mathrm{LH}$, estimulando crescimento final do folículo dominante aumentando a produção de esteróides que por feedback positivo, estimula aumento da freqüência de pulsos e provoca a onda préovulatória de LH e a primeira ovulação (Cardoso $\&$ Nogueira, 2007).

Produção de fêmeas de reposição necessita de conhecimentos dos processos fisiológicos que desencadeiam puberdade e primeira ovulação. Esses processos dependem primordialmente de nutrição, sanidade e genética que interferem na idade à puberdade que irá contribuir para o aumento da vida reprodutiva desse animal e proporcionando a possibilidade de gerar mais filhos, aumentando a eficiência reprodutiva e rentabilidade do sistema de produção (Oliveira et al., 2006). Sartori \& Mollo (2007) destacam que em condições de restrição alimentar, novilhas apresentaram início de puberdade retardada, prejudicando a atividade cíclica e diminuindo pulsos de LH necessário para o pico préovulatório, evidenciando assim a necessidade de aporte nutricional adequado, principalmente de reserva energética para manter a pulsatilidade de liberação de LH. Sendo que deficiência nutricional de novilhas é responsável por menores concentrações plasmáticas de glicose e insulina que são considerados mediadores nutricionais da reprodução.

A glicose é um carboidrato que é utilizado como principal fonte de energia pelo sistema nervoso central. Quando em estado de subnutrição severa, o animal entra em hipoglicemia, deprimindo o sistema nervoso, reduzindo secreção de GnRH pelo hipotálamo e menor atividade ovariana (Hess, 2005).

Já a insulina cuja principal função é regular os níveis de glicose no sangue, aumentando a absorção pelos tecidos (Squires, 2003) tem sido associado como mediador da informação do estatus nutricional do animal devido sua ligação 
com o metabolismo da glicose. Outros estudos demonstram a insulina como mediador dos efeitos nutricionais sobre a dinâmica folicular, facilitando a produção de IGF-1 pelo fígado, sendo importante no direcionamento dos eventos metabólicos essenciais a reprodução (Webb et al., 2004).

Dentro do sistema de produção do gado de corte nacional é comum encontrar novilhas entrando em acasalamento com idade avançada em média de 36 a 48 meses. Isso se deve a subnutrição destes animais na fase de cria por falta de planejamento alimentar de suas mães e na fase de recria por subnutrição (Santos et al., 2005) devido a sazonalidade da produção de forragens, manejo deficiente de pastagens e a inexistência de suplementação alimentar durante fase de crescimento desses animais (Santos \& Sá Filho, 2006).

Bezerras desmamadas precocemente, por volta dos 80 dias e alimentadas adequadamente, apresentam desempenho semelhante a bezerras desmamadas aos 150 dias de idade, sendo possível acasalarem aos 14-15 meses de idade, tendo a primeira cria por volta dos 24 meses, desde que criadas em sistemas intensivos com boas condições nutricionais. Bezerras desmamadas mais pesadas e com maiores ganhos de peso pós desmama se apresentam em melhores condições de acasalamento aos 14-15 meses de idade (Vaz \& Lobato, 2010).

Porém Potter et al. (2000) em estudos avaliando custos de produção em sistemas de acasalamento por volta dos 14-15 meses (precoce), 25-26 meses (intermediário) e 36 meses (tardio), observaram um custo de produção variável mais elevado no sistema precoce, decorrente principalmente dos custos com insumos agrícola para alimentação dos animais naquele ano, sendo o sistema intermediário apresentando melhor margem bruta e o tardio a pior. Sistemas utilizando introdução de novas tecnologias sempre apresentam melhores resultados quando comparados a sistemas "tradicionais" de produção, oferecem mais opções a serem exploradas e apresentam retorno mais rápido do investimento aplicado. No entanto devem ser observadas características como condições ambientais, características de puberdade da raça utilizada, condições de intensificação da produção, quantidade e qualidade da forragem disponível durante o ano e custos com insumos na suplementação.
Segundo Silva et al. (2005) a antecipação da idade ao primeiro acasalamento de 24 para 18 meses de idade é interessante biologicamente, porém é preciso que essas fêmeas tenham bom ganho de peso na fase de recria, chegando à estação de monta preparadas fisiologicamente, obtendo bons índices reprodutivos. Do contrário, o acasalamento por volta dos 18 meses apresenta menores taxas de prenhêz e menor eficiência quando comparado ao acasalamento aos 24 meses. Santos \& Sá Filho (2006), destacam que apesar das fêmeas zebuínas serem menos precoce à puberdade que fêmeas européias, utilizando um manejo nutricional adequado, estas podem entrar em puberdade por volta dos 18 a 20 meses tendo o primeiro parto por volta dos 28 meses de idade. No entanto, dietas suplementares visando alcançar um peso mínimo de 300 a $330 \mathrm{~kg}$ aos 18 meses podem não ser justificadas economicamente.

No Brasil, extensas áreas de pastagens associado aos climas tropicais e subtropicais que proporcionam bom desempenho de forrageiras e de sistemas pecuários sobre estas, é comum utilização de suplementação de baixo consumo ou a não suplementação dos animais de recria. Considerando a predominância do rebanho puro ou com algum grau de sangue zebuíno e sua entrada em puberdade mais tardia em relação a raças taurinas, o acasalamento de novilhas por volta dos 13-15 meses de idade vem sendo pouco estudada pelos pesquisadores e pouco aplicada pelos produtores (Rocha \& Lobato, 2002).

Pilau et al. (2005) afirmam que o uso de suplementos energéticos pré acasalamento alterando padrão de ganho de peso, escore de condição corporal, acúmulo de gordura precoce e proporcionando maior aporte de nutrientes, pode induzir puberdade precoce em novilhas.

$\mathrm{O}$ exato mecanismo no qual uma maior ingestão de energia pelos animais acelera a puberdade não é bem descrito, possivelmente mais de um fator está envolvido. Um aporte nutricional adequado proporciona maiores níveis de metabólitos e hormônios responsáveis pela ativação do eixo reprodutivo que sinaliza com produção e liberação de hormônios gonadotróficos. Também um maior ganho de peso proporciona deposição de gordura corpórea, que é responsável pela secreção de leptina que parece ser um sinalizador do e status corpóreo do animal induzindo a reprodução ou bloqueando em caso de baixas reservas corporais (Santos \& 
Sá Filho, 2006). Em bovinos, como em outras espécies, a maturação do eixo reprodutivo está associada a mudanças no eixo somatotrópico que envolve sinais metabólicos modulando os processos de entrada em puberdade e maturidade sexual (Maquivar \& Day, 2009).

Estudos realizados pela equipe de Gasser (Gasser et al., 2006a; b; c; d) na tentativa de avaliar a hipótese de que o eixo reprodutivo poderia ser ativado mais cedo quando fornecidas dietas ricas em concentrados (Tabela 1) a partir de 3 meses de idade induzindo a manifestação de puberdade precoce (antes de 300 dias de idade), compararam sistema de desmama precoce com suplementação rica em concentrado(AC; com ganho esperado de $1,5 \mathrm{Kg} /$ dia) e suplementação controle (CO; com ganho esperado de 0,75 $\mathrm{kg} / \mathrm{dia})$ em novilhas mestiças Angus e Simental, onde avaliaram padrão de onda folicular completa, entrada em puberdade, idade à puberdade e peso corporal à puberdade. Encontrando maior porcentagem de novilhas entrando em puberdade precoce, e entrando em uma idade inferior,quando comparadas novilhas que receberam dieta $\mathrm{AC}$ com as novilhas do grupo CO (Tabela 2).

Maior porcentagem de novilhas do grupo $\mathrm{CO}$ entrando em puberdade precoce no Exp2 (Gasser et al., 2006b) comparado aos demais experimentos $(56 \%, 0 \%, 0 \%$ e $20 \%$ nos experimentos $2,1,3$ e 4 respectivamente tabela. 2 ), pode ser explicado devido ao fato que os animais utilizados neste experimento foram submetidos a recursos alimentares excelentes antes da desmama precoce, visto uma boa disponibilidade de pasto oferecida naquele ano. Desta forma os animais apresentaram média de $35 \mathrm{~kg}$ de PC a mais na idade média de 103 dias que novilhas com mesma idade nos outros experimentos.

Tabela 1. Dietas fornecidas às novilhas experimentais dos grupos AC (alto concentrado) e CO (controle)

\begin{tabular}{llc}
\hline \multirow{2}{*}{ Ingredientes da dieta } & \multicolumn{2}{c}{ Dietas (\%) } \\
\cline { 2 - 3 } & $\mathrm{AC}$ & $\mathrm{CO}$ \\
\hline Milho & 60 & 30 \\
Pellets de alfafa 13\% PB & 10 & 30 \\
Casca de soja peletizada & 10 & 30 \\
Suplemento & 20 & 10 \\
Composição & & 14,1 \\
PB, \% & 14,1 & 1,70 \\
EM, Mcal/Kg & 2,02 & 1,09 \\
EMg, Mcal/Kg & 1,37 & \\
\hline
\end{tabular}

Evidenciando que o plano nutricional destas bezerras e suas mães durante seus primeiros meses de vida adiantaram o desenvolvimento do eixo reprodutivo, e consequente manifestação de puberdade precoce em 56\% no grupo CO e $100 \%$ no grupo AC. Também nesse Exp2, foi avaliado um grupo de novilhas que foi submetido a desmama tradicional (DT; 7 meses) e após esse período receberam a dieta controle até atingirem puberdade, com taxas de crescimento semelhantes ao grupo $\mathrm{CO}$ que foi desmamado precocemente, no intuito de avaliar o impacto da separação do bezerro e sua mãe na idade à puberdade e características de desenvolvimento folicular sem diferenças no PC.

Média de idade e $\mathrm{PC}$ na puberdade não diferiu entre as novilhas do grupo CO e DT, e uma proporção semelhante de novilhas manifestou puberdade precoce $(56 \%$ e $50 \%$ respectivamente). Dessa forma os autores demonstraram que em novilhas com crescimento a uma taxa típica, a idade a desmama (precoce ou tradicional) e a composição da dieta (CO, concentrado; DT, leite e pasto) não influenciou a entrada em puberdade.

Tabela 2. Novilhas que entraram em puberdade precoce e idade à puberdade nos grupos AC (alto concentrado) e CO (controle).

\begin{tabular}{llllllll}
\hline \multirow{2}{*}{ Experimento } & \multirow{2}{*}{$\mathrm{n}$} & \multicolumn{2}{l}{ Puberdade precoce $(\%)$} & \multicolumn{2}{l}{ Idade à puberdade (dias) } & \multicolumn{2}{l}{ Peso à puberdade $(\mathrm{Kg})$} \\
\cline { 3 - 7 } & & $\mathrm{AC}$ & $\mathrm{CO}$ & $\mathrm{AC}$ & $\mathrm{CO}$ & $\mathrm{AC}$ & $\mathrm{CO}$ \\
\hline Exp1 & 18 & $89 \mathrm{a}^{1}$ & $0 \mathrm{~b}^{1}$ & $262 \pm 10 \mathrm{a}^{1}$ & $368 \pm 10 \mathrm{~b}^{1}$ & $327 \mathrm{a}^{2}$ & $403 \mathrm{~b}^{2}$ \\
Exp2 & 18 & $100 \mathrm{a}^{1}$ & $56 \mathrm{~b}^{1}$ & $252 \pm 9 \mathrm{a}^{2}$ & $308 \pm 26 \mathrm{~b}^{2}$ & $373 \mathrm{a}^{1}$ & $370 \mathrm{a}^{1}$ \\
Exp3 & 10 & $80 \mathrm{a}^{1}$ & $0 \mathrm{~b}^{1}$ & $275 \pm 30 \mathrm{a}^{2}$ & $385 \pm 14 \mathrm{~b}^{2}$ & $310 \mathrm{a}^{1}$ & $310 \mathrm{a}^{1}$ \\
Exp4 & 30 & $67 \mathrm{a}^{2}$ & $20 \mathrm{~b}^{2}$ & $271 \pm 17 \mathrm{a}^{2}$ & $331 \pm 11 \mathrm{~b}^{2}$ & $331 \mathrm{a}^{1}$ & $325 \mathrm{a}^{1}$ \\
\hline
\end{tabular}

Médias seguidas de mesma letra na horizontal entre as variáveis estudadas, não diferem entre si à $(\mathrm{P}<0,01) \mathrm{e}$ $(\mathrm{P}<0,05)$ para ${ }^{1} \mathrm{e}^{2}$ respectivamente. 
A combinação entre desmama precoce $\mathrm{e}$ aumento da ingestão de energia dietética a base de milho éeficaz na indução de puberdade precoce em novilhas. Levando ao desenvolvimento folicular ovariano e secreção de hormônios semelhante a fases que antecedem a entrada em puberdade em idades mais tardias, proporcionando que estas fêmeas tenham vários ciclos estrais antes que entrem em sua primeira estação reprodutiva (Gasser et al., 2006b).

Estudos realizados com suplementação energética para recria de novilhas a pasto (Santos et al., 2004; Santos et al., 2005) encontraram desempenho satisfatório, permitindo ganhos de peso que possibilitem o primeiro serviço das novilhas por volta dos 18 a 24 meses de idade.Manejo de suplementação energética para novilhas em pastagens de gramíneas anuais aumentam a produção animal, e a receita bruta por hectare, sendo a margem bruta variável de acordo com o preço do suplemento utilizado. Substituição de polpa cítrica e casca de soja podem proporcionar ganho de peso por área similares aos encontrados quando utilizado milho grão, podendo ser mais viável economicamente.

Guardiero et al., (2010) avaliaram o efeito da suplementação com gordura protegida ruminal na dieta de novilhas Nelore e sua influência no tamanho folicular, volume luteal e nas concentrações séricas de progesterona. Foram utilizadas 40 novilhas que receberam dietas balanceadas isoenergéticas e isoproteicas, que atendiam as exigências de mantença para novilhas em crescimento. Os autores verificaram que o consumo de gordura protegida, na dose de $100 \mathrm{~g}$ dia, afetou as concentrações circulantes de progesterona, provavelmente pela diminuição de metabolismo hepático dos esteróides e mecanismos anti-luteolíticos, porém não alterou o tamanho do folículo ovulatório e volume luteal em novilhas Nelore suplementadas a pasto.

Para Cooke (2011) em situações de pastagens de baixa qualidade, a ingestão da forragem pode ser limitada pelo seu baixo teor protéico, que declina rapidamente à medida que o teor de proteína bruta da forragem alcança valores menores que 7\%, limitando a atividade microbiana (Moore et al., 1991). Dessa forma fornecimento de proteína via suplementação promove melhoria no aporte de nutrientes limitantes (proteína) para os microorganismos que degradam fibra, o que aumenta a digestibilidade da FDN e aumento de ingestão de forragem que é a principal fonte de energia. Aumento da ingestão de alimentos e sua digestibilidade melhoram o aporte protéico e energético, proporcionando ganho de peso adequado induzindo puberdade em novilhas.

Visando diminuir custos, tem se utilizado fontes de nitrogênio não protéico (NNP) em rações bovinas em substituição a fontes protéicas naturais, porém, inclusão de altos níveis de NNP na dieta pode influenciar o desempenho reprodutivo de fêmeas. Em vacas não foram observadas diferenças na eficiência reprodutiva quando suplementadas com dietas contendo NNP, no entanto animais em crescimento como novilhas de reposição, apresentam melhores resultados quando suplementadas com fontes de proteína naturais, devido necessidade de aminoácidos específicos para o crescimento corporal (Cooke, 2011).

Pate et al (1995) avaliaram suplementos a base de melaço com diferentes fontes de proteína bruta, e observaram maior taxa de crescimento ao dia, maior peso corporal para entrada em estação de monta e maior taxa de prenhes ao final de uma estação de monta de 60 dias em novilhas com fonte de proteína bruta natural (farinha de penas) quando comparadas a suplementos protéicos a base de uréia.

Estratégias de suplementação que compensem certa desvantagem genética apresentada por animais zebuínos com respeito à precocidade sexual e menor disponibilidade de nutrientes disponíveis em sistemas de cria à base de forragens se tornam necessárias visando redução da idade ao primeiro serviço de novilhas e melhora na eficiência reprodutiva das fêmeas do rebanho (Cooke, 2011)

\section{Programação do desenvolvimento fetal}

Ingestão adequada de alimentos suprindo necessidades fisiológicas é essencial para crescimento e desenvolvimento do organismo. Deficiência de nutrientes em períodos críticos do desenvolvimento dos sistemas fisiológicos principalmente durante gestação e lactação, pode acarretar alterações a curto e longo prazo, predispondo a patologias na fase adulta (Leandro et al., 2009).

A programação fetal é o conceito de que um estímulo materno ocorrido em determinadas fases da gestação, possa interferir no desenvolvimento fetal com efeitos ao longo prazo sobre a saúde, sendo esses estímulos benéficos ou maléficos, 
interferindo no crescimento de um indivíduo após seu nascimento. Esse conceito começou a ser estudado inicialmente pela ciência médica, quando se verificou que populações que passaram fome durante alguma fase da gestação, mesmo depois de restabelecida as condições nutricionais adequadas e seus bebês nascidos com peso normal, no futuro essas crianças desenvolveram problemas de saúde com taxas superiores a população controle no mesmo país (Barker \& Clark, 1997). Desde então, estudos tem se avançado buscando entender os mecanismos no qual a nutrição afeta a saúde e desenvolvimento pós-natal (Pires et al., 2011).

Em sistemas de produção, é importante buscar a expressão genética máxima do indivíduo, sendo assim, retardo no crescimento intra-uterino nas fases embrionárias e fetais afetando o crescimento na fase adulta, se torna uma preocupação na produção de animais domésticos. Restrição do crescimento fetal pode provocar aumento de mortalidade neonatal, nanismo, ineficiência em conversão alimentar e diferença no diâmetro das fibras musculares afetando a composição e qualidade da carne ( $\mathrm{Wu}$ et al., 2006).

Hess (2008) destaca que a maioria dos sistemas de criação de bovinos, são sistemas extensivos, onde a base da alimentação é a forragem consumida. Em determinados períodos do ano, essa forragem é de baixa quantidade e qualidade, não atendendo as exigências que garanta crescimento, gestação e lactação sem suplementação adicional. A respeito do desenvolvimento fetal, as fases de terço inicial e médio da gestação demandam menos nutrientes comparadas ao terço final, mas não menos importantes de serem supridas, proporcionando crescimento adequado até o nascimento da prole.

A maioria das fibras musculares esqueléticas é formada a partir dos somitos, que se diferenciam originando o dermomiótomo, localizado dorsalmente no embrião, que será responsável pela formação da derme e musculatura esquelética. Esse processo envolve ativação, proliferação e diferenciação de várias linhagens de células miogênicas e expressão de fatores de regulação miogênica (Dal Pai-Silva \& Carvalho, 2007).

Animais destinados para produção de carne necessitam do desenvolvimento de músculo esquelético (Figura 1), por isso o desenvolvimento fetal se torna importante, onde irá ocorrer aumento do número de fibras musculares (hiperplasia) visto que após o nascimento só ocorre aumento de massa muscular por hipertrofia. Diminuição no número de fibras musculares da prole devido a subnutrição materna na gestação irá afetar negativamente o seu desempenho (Zhu et al., 2004), pois o músculo estriado esquelético está envolvido com a locomoção, postura, movimentos respiratórios e formação do maior tecido constituinte do corpo (Dal Pai-Silva \& Carvalho, 2007).

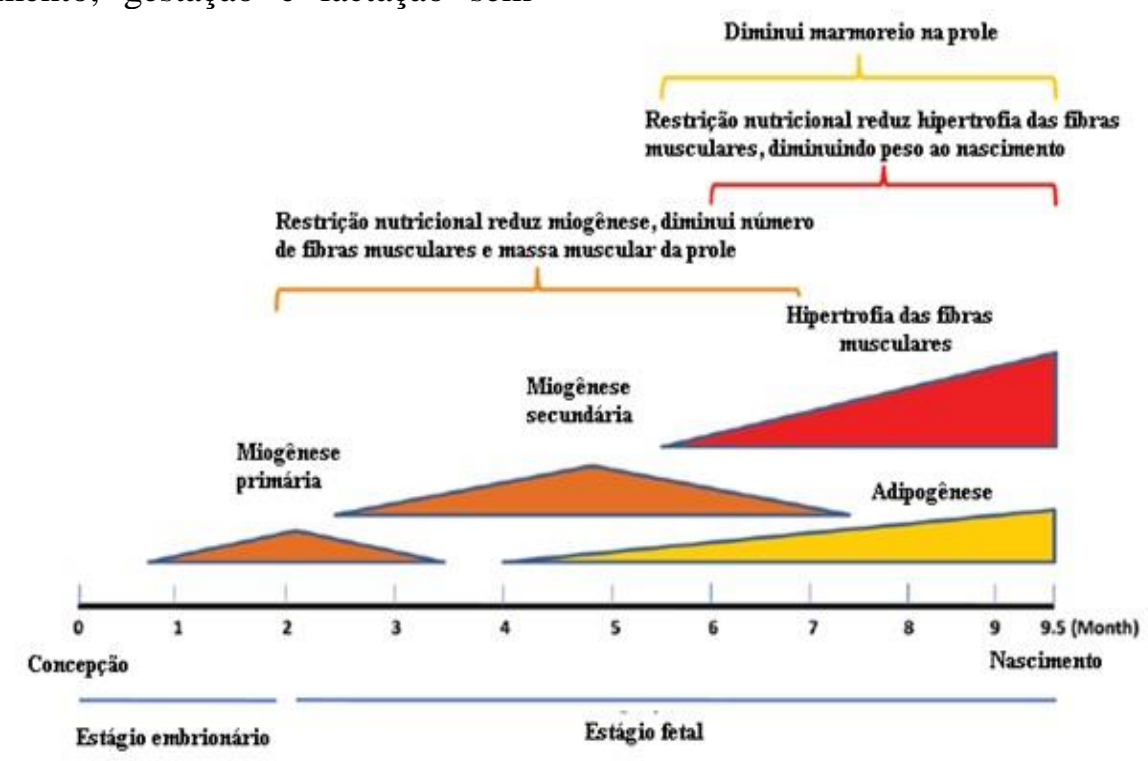

Figura 1. Interação nutrição produção fibras musculares e formação de adipócitos no estágio fetal bovino. Restrição alimentar no terço inicial e médio da gestação reduz número de fibras musculares, enquanto restrições alimentar no terço final da gestação reduz hipertrofia das fibras musculares e formação dos adipócitos da prole. Adaptado de Du et al., (2010). 
As fibras musculares esqueléticas podem ser primárias (menor quantidade) e secundárias (maior quantidade). Entre as fibras musculares estão presentes as células satélites, que possuem diferentes graus de comprometimento miogênico. Uma pequena parte considerada multipotentes podem se diferenciar em adipócitos ou fibroblastos em vez de células miogênicas, sendo importante no processo de formação de adipócitos e marmoreio (Kuang et al., 2008 citados por Du et al., 2010)

A formação de adipócitos (Figura 1) que será responsável pelo acúmulo de gordura intramuscular na carcaça, responsável por maior flavor da carne, também ocorre na fase fetal e em menor quantidade na fase pós natal, sendo cessada após cerca de 200 dias de vida em bovinos (Du et al., 2010).

Martins et al. (2007) utilizaram 170 novilhas, cujas mães foram suplementadas no terço final da gestação ou inicio da lactação, e avaliaram seu crescimento subseqüente e reprodução. Fêmeas no final de gestação foram divididas em dois grupos: GS (receberam suplemento fornecido3 vezes na semana com $42 \%$ de proteína bruta, 73,3\% NDT - 50\% de farelo de girassol, 47,9\% de farelo de algodão e $2,1 \%$ de ureia) e NS (grupo não suplementado), sendo ambos mantidos em pastagens nativas. Não foi observada diferença no peso ao nascimento das bezerras entre os grupos GS e NS $(\mathrm{P}>0,10)$. Porém, novilhas filhas do GS apresentaram maior peso corporal em comparação ao grupo NS aos 205 dias $(\mathrm{p}=0,07)$, também apresentaram maior taxa de prenhes ao final de sua primeira estação de monta $93 \%$ VS $80 \%(\mathrm{P}<0,04)$, e um maior número de novilhas filhas do GS pariram nos primeiros 21 dias de estação $77 \%$ VS $49 \%$. Sugerindo o efeito da dieta materna na programação fetal sobre a fertilidade das novilhas posteriormente, influenciando no desenvolvimento dos tecidos reprodutivos do feto.

Em estudo semelhante Stalker et al., 2006, também avaliaram a suplementação protéica no terço médio da gestação de 136 vacas por 3 anos. No primeiro ano 136 fêmeas mestiças no final de gestação foram divididas em dois grupos: GS (receberam suplemento fornecido 3 vezes na semana com $42 \%$ de proteína bruta, $73,3 \%$ NDT - 50\% de farelo de girassol, 47,9\% de farelo de algodão, 2,1\% de ureia e 66.139 UI de vitamina A $/ \mathrm{kg}$ ) e NS (grupo não suplementado), sendo ambos mantidos em pastagens nativas, no segundo ano as vacas foram transferidas para o tratamento oposto, e no terceiro ano foram transferidas de volta para o tratamento original. Vacas suplementadas durante o período pré-parto não perderam peso durante o período, enquanto que vacas sem suplementação perderam $29 \mathrm{~kg}$ de peso corporal, também vacas do GS tiveram maior escore de condição corporal do que vacas NS. No entanto, melhor escore corporal não resultou em melhores taxa de prenhes. Bezerros nascidos de vacas GS nasceram 3 dias mais tarde na estação de parição do que bezerros nascidos de vacas NS $(\mathrm{P}=0,01)$, mas o peso ao nascer não foi afetado pelo tratamento $(\mathrm{P}=0,29)$. No entanto, peso ao desmame e ganho médio diário do nascimento ao desmame foram maiores para os bezerros nascidos de vacas suplementadas em comparação com bezerros de vacas não suplementadas. A porcentagem de bezerros vivos ao desmame foi maior para vacas GS em comparação com vacas NS. Em análise econômica, a alimentação materna pré-parto aumentou o retorno líquido em U\$ 25,38 por bezerro desmamado devido maior peso a desmama e viabilidade dos bezerros, já após o abate aumentou em U\$ 45,8 por boi terminado devido maior número de animais desmamados. Estes resultados justificam a prática de alimentação suplementar protéica em vacas em gestação.

A composição do marmoreio da carcaça sendo afetada na fase fetal foi comprovada quando se utilizaram vacas mestiças mantida em pastagem nativa com 5,4\% de PB (GC) ou em pastagens melhoradas com cerca de $11,1 \%$ de PB (PM) durante o terço médio da gestação (150-210 dias de gestação), após esse período foram mantidas em condições semelhantes de pastagens nativas. Os bezerros destas vacas foram desmamados aos 190 dias e entraram em confinamento aos 315 dias de idade para serem abatidos por volta dos 15 meses. Foram coletados amostras de músculo Longissimus e tecido adiposo. O peso de entrada no confinamento dos novilhos não diferiu $(\mathrm{P}=$ 0,71 ) entre os tratamentos GC e PM, porém no momento do abate, bois filhos de vacas do grupo $\mathrm{PM}$ apresentaram maior peso vivo $(\mathrm{P}=0,04)$ do que bois filhos de vacas GC. Área de olho de lombo, peso do músculo Longissimus, gordura pélvica e cárdica foram semelhantes entre os grupos $(\mathrm{P}>0,12)$. Espessura de gordura na décima segunda costela $(\mathrm{P}=0,05)$ foi maior para os bois filhos de vacas do grupo PM, também o número de tecido adiposo por campo tendeu a serem maiores $(\mathrm{P}=0,09)$. Mostrando que 
melhores condições nutricionais, através de melhores pastagens durante a gestação melhoram a deposição de tecido adiposo em novilhos (Underwood et al., 2008).

Em outro estudo Tong et al. (2008) utilizaram ovelhas superalimentadas SA $(150 \%$ das recomendações do NRC) comparadas ao grupo controle GC ( $100 \%$ das recomendações do NRC) para avaliar adipogênese na fase fetal que irá proporcionar $\mathrm{o}$ acúmulo de gordura intra muscular que confere sabor e determina qualidade da carne. As fêmeas foram suplementadas até 75 dias de gestação, quando foram abatidas e os fetos analisados. Neste estudo a suplementação materna durante a gestação proporcionou maior adipogênese, melhorando o marmoreio e qualidade da carne, segundo o autor, mais estudos devem ser realizados, mas estes resultados podem ser aplicados em bovinos de corte e em outros animais de produção de carne.

$\mathrm{Du}$ et al. (2010) ressalta que manejo nutricional buscando maior quantidade de adipócitos intramuscular em bovinos de corte será mais eficaz na fase fetal (Figura 2) devido maior presença de células multipotentes no músculo esquelético, que diminuem gradualmente após o nascimento, sendo praticamente inexistentes após 250 dias de idade.

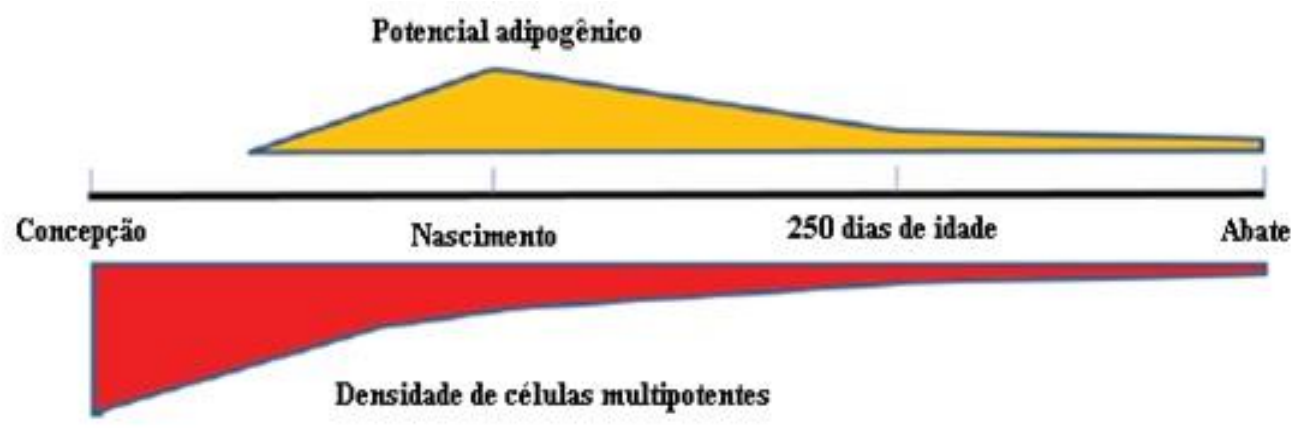

Figura 2. Densidade de células multipotentes e potencial adipogênico do músculo esquelético de bovinos. Adaptado de Du et al., (2010).

Por outro lado a super nutrição ou obesidade materna durante a gestação também podem interferem negativamente no desenvolvimento da prole, levando a efeitos prejudiciais persistentes, como, pré-disposição a obesidade e diabetes tipo II. Provavelmente isso ocorra devido àmiogênese, adipogênese e fibrogênese derivarem de células troncos mesenquimais, e por algum motivo, a obesidade materna induziria $\mathrm{o}$ aumento da gordura e tecido conjuntivo muscular e diminuiria o número e diâmetro das fibras musculares. Como o desenvolvimento muscular esquelético é fundamental para o desenvolvimento da prole, desvio na diferenciação de células tronco mesenquimais em direção a adipogênese provocará efeitos permanentes sobre as propriedades do músculo esquelético (Du et al., 2009).

Santello et al. (2010) trabalharam com ovelhas Santa Inês alimentadas com diferentes níveis de proteína bruta no terço inicial da gestação $(15,2 ; 22,5 ; 26,5$ e $35,6 \%$ de PB) mantidas em pastagens de capim Aruana (Panicum maximum cv. Aruana) de forma a receberem 80, 100, 120 e $140 \%$ das exigências de
PB. Ao nascimento dos cordeiros foram realizadas biópsias no músculo semitendinosus esquerdo, para avaliar o número e diâmetro das fibras musculares. Não houve efeito da alimentação materna no terço inicial da gestação sobre peso ao nascimento dos cordeiros, aos 30 dias de idade e ao desmame. Também não houve diferença do desempenho dos cordeiros na fase de terminação, provavelmente por não haver diferença entre os cordeiros no número $\mathrm{e}$ diâmetro das fibras musculares ao nascimento. Implicando que o teor de PB de dietas para ovelhas no inicio de gestação não influência no desenvolvimento muscular do feto. Porém o autor destaca que provavelmente esses resultados foram encontrados devido os teores de PB terem sido suficientes para suprir as exigências nutricionais das ovelhas no terço inicial da gestação, não interferindo no crescimento fetal. Segundo Everitt (1967) citado por Santello et al., (2010) somente uma restrição severa no terço inicial da gestação levaria a redução do crescimento fetal e menor peso ao nascimento de cordeiros. 
Mexia et al. (2006) trabalhando com ovelhas Santa Inês, avaliaram o desenvolvimento ponderal do nascimento ao desmame, número e diâmetro de fibras musculares do músculo semitendinosus de cordeiros nascidos de fêmeas criadas em pastagens de capim Tanzânia (Panicum maximum Jacq.) recebendo suplementação alimentar em diferentes fases da gestação (GC- Grupo controle- mantidas em pastagem recebendo $2 \mathrm{~kg}$ resíduo de mandioca/dia, TI- Terço inicial- manejo do GC+400g de suplemento com $18 \%$ PB, TMTerço médio- manejo do $\mathrm{GC}+400 \mathrm{~g}$ de suplemento com $18 \%$ PB e TF- Terço final manejo do GC+600g de suplemento com $24 \%$
PB). O peso dos cordeiros ao nascimento, aos 30 dias de idade e ao desmame aos 60 dias não teve diferença entre os tratamentos (Tabela 3); no entanto no peso corporal ao nascimento houve diferença numérica, sendo os cordeiros do GC $(3,76 \mathrm{Kg}) 6,47 \%$ inferior a média dos tratamentos $(4,02 \mathrm{Kg})$ e $16,26 \%$ abaixo do peso ao nascimento de cordeiros cujas fêmeas receberam suplementação no terço inicial da gestação $(4,49$ $\mathrm{kg}$ ). Dessa forma, programação fetal deve ser mais estudada visto o peso ao nascer em cordeiros ser um dos parâmetros produtivos de maior importância na taxa de sobrevivência neonatal de cordeiros.

Tabela 3 - Médias dos pesos corporais ao nascimento (PC), aos 30 dias de idade (PC30), aos 60 dias de idade (PC60) e ganho médio diário (GMD 0-60) de acordo com o período da suplementação materna.

\begin{tabular}{lcccc}
\hline Tratamento & PCN & PC30 & PC60 & GMD 0-60 \\
\hline Controle & 3,76 & 8,67 & 15,93 & 0,20 \\
Terço inicial & 4,49 & 10,03 & 17,94 & 0,22 \\
Terço médio & 4,20 & 9,60 & 17,47 & 0,22 \\
Terço Final & 4,26 & 9,47 & 16,93 & 0,21 \\
Média Geral & 4,02 & 9,19 & 16,40 & 0,21 \\
CV $(\%)^{*}$ & 14,16 & 19,12 & 17,69 & 21,27 \\
\hline
\end{tabular}

$* \mathrm{CV}=$ coeficiente de variação

Para sermos capazes de usar informações descritas nos trabalhos realizados, é preciso avançar os estudos além de associações epidemiológicas. É preciso identificar os fatores que limitam nutrição fetal e como o feto se adapta a uma oferta limitada de nutrientes. Peso ao nascer por si só, é um fator inadequado para mensurar os danos causas pela desnutrição materna durante a gestação. Estudo realizado com animais de produção tem demonstrado melhor os efeitos em longo prazo do desenvolvimento fetal (Barker \& Clark, 1997).

Funston et al., (2010) ressalta que subnutrição materna podem afetar peso ao nascimento da prole, crescimento, reprodução, peso e qualidade da carcaça. Deficiências no início da gestação afeta o desenvolvimento da placenta alterando sua vascularização, enquanto no terço médio e final da gestação afeta o desenvolvimento final de órgãos, formação do músculo esquelético e adipócitos e absorção de nutrientes pelos tecidos importantes na reprodução. Esses mecanismos não são bem estudados, dessa forma manejos conhecidos de manipular o escore de condição corporal devem ser tomados visando diminuir perda de peso corporal de fêmeas gestantes.

\section{Femeas prenhes pré e pós parto}

Para um sistema de produção de bovinos de corte ser rentável e eficiente ele depende de fatores primários como: peso de bezerros desmamados, lucro líquido com a venda dos bezerros, porcentagem de bezerros desmamados e custo para manter uma fêmea produzindo estes bezerros. Dessa forma é preciso fornecer condições nutricionais suficientes para que esta vaca mantenha seu organismo, retorne a atividade cíclica normal pós-parto em período mais curto possível, conceba novamente nos primeiros dias de estação de monta, produza bezerros pesados, tenha partos sem dificuldade e produza leite suficiente para nutrir seu bezerro adequadamente até o período de desmama por volta de 7-8 meses de idade. Custos com alimentação (forragem e suplementação) representam de $50-70 \%$ do custo total de mantença da matriz no rebanho, dessa forma, ela deve ser eficiente e produzir um bezerro por ano, que é o produto a ser vendido obtendo receita. Caso contrário, este animal terá os mesmos custos com alimentação e manejo e não proporcionará retorno financeiro (Fluharty, 2009). 
A demanda de nutrientes pelos órgãos definirá a partição e utilização destes. Após o parto a baixa ingestão de nutrientes está associada à perda de peso, diminuição do escore de condição corporal (ECC), atraso na primeira ovulação pósparto, decréscimo na atividade luteal e anestro (Ferreira, 1993). O balanço de energia líquida (BEL) é a diferença entre a energia consumida e a necessária para manutenção e produção (Santos \& Sá Filho, 2006). No pós-parto geralmente os animais entram em estado de balanço energético líquido negativo, onde apresentam um aumento de requerimento nutricional excessivo acompanhado de uma capacidade de ingestão de matéria seca reduzida, que só irá alcançar capacidade máxima por volta de 4-6 semanas após o pico de produção de leite (Bell, 1995).

Para Calegare et al. (2010) o impacto causado por deficiência energética da dieta causa efeitos negativos na eficiência reprodutiva, que é o fator limitante na eficiência de produção de carne.

Após absorção, os nutrientes são direcionados para os tecidos com maior prioridade na seguinte ordem: metabolismo basal, atividades diárias, crescimento, reservas corporais básicas, lactação, acúmulo de reservas corporais, ciclo estral e início de gestação. Sendo assim, nutrientes destinados ao inicio da atividade reprodutiva serão direcionados quando as demais prioridades forem atendidas, tecido mamário tem prioridade sobre funções reprodutivas que é o primeiro sistema afetado em caso de déficit energético (Maggioni et al., 2008).

Durante a lactação a glândula mamária se torna um tecido com alta taxa metabólica com prioridade no direcionamento de substratos, chegando a usar de $60-85 \%$ da glicose disponível pelo corpo, sendo cerca de $80 \%$ usados na síntese de lactose, isso ocorre, pois o úbere tem certa facilidade na captação de glicose nas células pelas moléculas de transporte de glicose, o que não acontece nos demais tecidos corpóreos (Zhao et al., 1996 citados por Leroy et al., 2009).

A utilização da glicose no sistema nervoso tem função importante, secretando aminoácidos nesses tecidos, essenciais na formação dos hormônios peptídeos (McCann \& Hansel, 1986, citados por Ferreira (1993). O crescimento folicular, ovulação e fase luteínica são reguladas pelo eixo reprodutivo hipotálamo-hipófisegonadal que por feedback regula a produção e secreção dos hormônios gonadotróficos. $\mathrm{O}$ hormônio liberador de gonadotrofinas $(\mathrm{GnRH})$ é um hormônio glicoprotéico produzido no hipotálamo e secretado na hipófise induzindo liberação do FSH e LH que também é influenciado pelos níveis séricos de estrógeno e progesterona circulantes (feedback). Situações de subnutrição levam a inadequada liberação de $\mathrm{GnRH}$, alterando atividade ovariana. A nutrição altera os níveis de glicose, aminoácidos e hormônios como insulina, fator de crescimento semelhante à insulina (IGF-1) e hormônio do crescimento $(\mathrm{GH})$, que de certa forma alteram padrões de produção de estrógeno e FSH necessário para liberação de GnRH (Calegare et al., 2010).

Baixo desempenho reprodutivo também pode ser associado a um consumo baixo ou excessivo de nutrientes, minerais e vitaminas (Tabela 4).

Tabela 4. Deficiência e excesso de nutrientes na dieta e sua relação com a reprodução.

\begin{tabular}{lc}
\hline Nutrientes & Efeito \\
\hline Excesso de energia & Baixa taxa de concepção, retenção de placenta \\
Déficit de energia & Atraso na puberdade, supressão da ovulação e estro \\
Excesso de proteína & Baixa taxa de concepção \\
Déficit de proteína & Supressão de estro, baixa taxa de concepção, parto prematuro \\
Déficit de vitamina A & Anestro, aborto, natimortos, retenção de placenta \\
Déficit de vitamina D & Má formação esquelética \\
Déficit de vitamina E & Retenção de placenta \\
Déficit de Ca & Má formação esquelética \\
Déficit de P & Anestro, estro irregular \\
Déficit de I & Anomalias, retenção de placenta \\
Déficit de Se & Retenção de placenta \\
\hline
\end{tabular}

Fonte: Adaptado de Bearder \& Fuquay (2000), citados por Pires et al. (2011). 
Paulino et al. (2010) destaca que executar experimentos para determinar exigências nutricionais de vacas em lactação não são muito simples. Isto porque, determinar exigência nessa categoria envolve mensuração de produção de leite, para output energético da vaca e input no consumo de energia metabolizável do bezerro, sua composição e composição corporal do conjunto vaca:bezerro. Conhecendo a produção de leite, é possível determinar a quantidade de energia secretada via leite e o momento em que a energia fornecida pelo leite não é suficiente para o máximo crescimento do bezerro, sendo necessária utilização de suplementação alimentar.

\section{Exigências nutricionais de vacas}

De acordo com Paulino et al. (2010), as exigências de energia líquida de mantença $\left(\mathrm{EL}_{\mathrm{m}}\right)$ de vacas segundo o NRC (2000) seria de 77
$\mathrm{Kcal} / \mathrm{Kg} \quad \mathrm{PC}^{0,75}$,recomendando-se desconto de $10 \%$ para fêmeas zebuínas e acréscimo de $20 \%$ em fêmeas lactantes, as exigência de $\mathrm{EL}_{\mathrm{m}}$ para vacas Nelores em lactação seriam de 83,16 $\mathrm{Kcal} / \mathrm{kg} \quad \mathrm{PC}^{0,75}$, semelhantes aos valores reportados por Fonseca et al. (2009) de 97,84 $\mathrm{Kcal} / \mathrm{kg} \mathrm{PC}^{0,75}$. Ainda neste estudo foi determinada a exigência de energia metabolizável para mantença $\left(\mathrm{EM}_{\mathrm{m}}\right)$, resultando em uma eficiência de utilização $\left(\mathrm{k}_{\mathrm{m}}\right)$ de 0,70 resultando em $\quad \mathrm{EM}_{\mathrm{m}}: \quad 140,17 \mathrm{Kcal} / \mathrm{Kg}^{0,75} \quad(97,84 / 0,70)$. Corroborando com Calegareet al.. (2007) que encontrou valores de $\mathrm{EM}_{\mathrm{m}}: 141,3 \mathrm{Kcal} / \mathrm{Kg}^{0,75}$ para vacas Nelore em lactação.

$\mathrm{Na}$ tabela 5 estão descritas as exigências de energia para mantença de vacas Nelore em lactação, expressas em $\mathrm{EL}_{\mathrm{m}}, \mathrm{EM}_{\mathrm{m}} \mathrm{e}$ nutrientes digestíveis totais (NDT).

Tabela 5. Exigência de energia para mantença de vacas Nelore em lactação conforme peso corporal.

\begin{tabular}{lccc}
\hline $\mathrm{PC}$ & $\mathrm{EM}_{\mathrm{m}}$ & $\mathrm{EL}_{\mathrm{m}}$ & $\mathrm{NDT}(\mathrm{kg} / \mathrm{dia})$ \\
\hline 300 & 9,29 & 6,50 & 2,57 \\
350 & 10,42 & 7,29 & 2,88 \\
400 & 11,53 & 8,07 & 3,19 \\
450 & 12,59 & 8,81 & 3,48 \\
\hline
\end{tabular}

$\mathrm{EM}_{\mathrm{m}}: 140,17 \mathrm{Kcal} / \mathrm{PCVZ}^{0,75}$; PCVZ/PC: 0,894; $\mathrm{k}_{\mathrm{m}}$ : 0,70; PC: peso corporal; EMm: energia metabolizável de mantença; $\mathrm{EL}_{\mathrm{m}}$ : energia líquida de mantença; NDT: nutrientes digestíveis totais. Adaptado de Paulino et al., (2010)

No pós-parto é comum a perda de peso nas primeiras semanas, perdas de $10-15 \%$ do $\mathrm{PC}$ não afetam o reinicio da atividade ovariana cíclica e restabelecimento de ciclos estrais normais em vacas parindo em bom estado de condição corporal. Porém em condições de subnutrição o animal ativa mecanismos, retirando massas corporais podendo atrasar o aparecimento do primeiro estro (Ferreira, 1993).
Paulino et al. (2010) descrevem as exigências de $\mathrm{EL}_{\mathrm{m}}, \mathrm{EM}_{\mathrm{m}} \mathrm{e}$ NDT para ganho de peso de vacas Nelore em lactação (Tabela 6). E exigências de energia digestível (ED) e NDT por Kg de leite produzido por vacas Nelore que seriam de 1,30 Mcal e $0,295 \mathrm{Kg} / \mathrm{Kg}$ de leite respectivamente.

Exigências energéticas de mantença é a quantidade de alimento consumida necessária para manutenção do peso do animal.

Tabela 6. Exigências de energia para ganho de um quilograma de peso corporal de vacas Nelore em lactação

\begin{tabular}{lccc}
\hline \multirow{2}{*}{ Peso corporal } & \multicolumn{3}{c}{ Exigências $^{1}$} \\
\cline { 2 - 4 } & ELg (Mcal/kg) & EMg (Mcal/dia) & NDT (Kg) \\
\hline 300 & 3,58 & 8,14 & 2,25 \\
350 & 3,72 & 8,45 & 2,34 \\
400 & 3,84 & 8,73 & 2,41 \\
450 & 3,95 & 8,98 & 2,48 \\
\hline
\end{tabular}

${ }^{\mathrm{T}}$ Exigências para ganho de $1 \mathrm{Kg}$ de peso corporal. PCVZ: 0,894; GPCVZ: 0,936xGPC; $\mathrm{k}_{\mathrm{g}}$ : 0,44; EMg $_{\mathrm{g}}$ : energia metabolizável para ganho; NDT: nutrientes digestíveis totais

Fêmeas em fase reprodutiva apresentam de $60-75 \%$ da energia consumida para mantença, que seria a energia metabolizável perdida na forma de calor. Mesmo sendo subjetivo o escore de condição corporal (ECC) é uma ferramenta importante, servindo como indicador das reservas corporais do animal num dado momento, ECC muito baixo ou alto no pré-parto podem 
influenciar em um maio anestro pós-parto, reduzindo as taxas de concepção e prenhes na estação de monta subsequente (Calegare et al., 2010).

Na tabela 7 estão descritas as exigências de proteína para mantença de vacas Nelore em lactação, expressas em $\mathrm{PM}_{\mathrm{m}}(\mathrm{g}), \mathrm{PB}(\mathrm{g})$. Já a exigência de proteína metabolizável para produção de leite em vacas Nelore seria de 52,8 $\mathrm{g} / \mathrm{kg}$ de leite.

Tabela 7. Exigência de proteína para mantença de vacas Nelore em lactação conforme peso corporal.

\begin{tabular}{lcc}
\hline PC & $\mathrm{PM}_{\mathrm{m}}(\mathrm{g})$ & $\mathrm{PB}(\mathrm{g})$ \\
\hline 300 & 288,34 & 455,65 \\
350 & 323,68 & 512,1 \\
400 & 357,77 & 565,53 \\
450 & 390,81 & 617,98 \\
\hline
\end{tabular}

\section{Considerações finais}

Suplementação de fêmeas bovinas em sistema de pastejo de gramíneas tropicais é fundamental para aumentar a produtividade e eficiência reprodutiva em sistemas de produção de bovinos de corte. Porém mais estudos devem ser desenvolvidos a fim de determinar com maior precisão as exigências nutricionais para cada categoria, e determinar quando usar suplementação energética e protéica mantendo um custo benefício viável.

Outro fator que não pode ser deixado de lado são os crescentes indícios da programação do desenvolvimento fetal tendo influência direta do nascimento à vida adulta do animal, sendo possível intervir visando maior deposição de fibras musculares e adipócitos que proporcionaria um melhor desenvolvimento da prole no futuro, ou até mesmo pensando em eficiência reprodutiva, precocidade sexual e saúde geral dessa prole.

Sistemas otimizados com intervalos entre partos de 12-13 meses, a suplementação estratégica se torna indispensável, buscando melhorar escore de condição corporal antes do parto, reduzindo o período de serviço que não deve exceder 90 dias.

É importante conhecer os mecanismos pelo qual mediadores nutricionais e hormônios atuam sobra a reprodução, identificando os múltiplos fatores que devem ser considerados buscando um entendimento dessa interação.

\section{Referências Bibliográficas}

ANUALPEC. Anuário da Pecuária Brasileira, 2010. São Paulo: Instituto FNP.
Amaral, T.B., Corrêa, E.D. \& Costa, F.P. 2005. Suplementação alimentar de vacas de cria: quando e por que fazer?, $1^{\circ}$ edição, Campo Grande-MS, Embrapa Gado de Corte, 23p.

Barker, D.J.P. \& Clark, P.M. 1997. Fetal undernutrition and disease in later life. Reviews of Reproduction, 2, 105-112.

Bell, A.W. 1995. Regulation of organic nutrient metabolism during transition from pregnancy to early lactation. Journal of Animal Science, 73, 2804-2819.

Borges, A.M., Carvalho, B.C. \& Ruas, J.R.M. 2009. Manejo reprodutivo da vaca mestiça: estado da arte. Anais do Congresso Brasileiro de Reprodução Animal. Belo Horizonte-MG, 572p.

Calegare, L.N.P. 2004. Exigências e eficiência energética de vacas de corte Nelore e de cruzamentos Bos taurus x Nelore. PiracicabaSP, ESALQ, Escola Superior de Agricultura Luís de Queiroz. Dissertação (Mestrado em Zootecnia), 79p.

Calegare, L.N.P., Albertini, T.Z. \& Lanna, D.P.D. 2010. Eficiência da vaca de cria. Capítulo 8, Bovinocultura de corte, Piracicaba: FEALQ, 1, 760p

Cardoso, D. \& Nogueira, G.P. 2007. Mecanismos neuroendócrinos envolvidos na puberdade de novilhas. Arquivos de Ciência Veterinária e Zoologia.10, 59-67.

Cooke, R F. 2011. Estratégias de suplementação para fêmeas de corte mantidas em pasto. In: Anais do XV curso novos enfoques na produção e reprodução de bovinos, Uberlândia-MG, p.226-242. 
Dal Pai-Silva, M. \& Carvalho, R. F. 2007. Mecanismos celulares e moleculares que controlam o desenvolvimento e o crescimento muscular. Revista Brasileira de Zootecnia, 36, 21-31.

Du, M., Tong, J., Zhao, J., Underwood, K.R., Zhu, M., Ford, S.P. \& Nathanielsz, P.W. 2010. Fetal programming of skeletal muscle development in ruminant animals. Journal Animal Science. 88, 51-60.

Du, M., Yan, X., Tong, J.F., Zhao, J. \& Zhu, M.J. 2009. Maternal obesity, inflammation, and fetal skeletal muscle development. Biology of Reproduction, 10, 1-22.

Ferreira, A.M. 1992. Efeito da amamentação na reprodução de vacas. Pesquisa Agropecuária Brasileira. 27, 27-39.

Ferreira, A.M. 1993. Nutrição e atividade ovariana em bovinos: uma revisão. Pesquisa Agropecuária Brasileira. 28, 1077-1093.

Fluharty, F.L. 2009. Manejo nutricional e requisitos nutricionais de vacas de corte no pré e pós-parto. In: Anais do XIII curso novos enfoques na produção e reprodução de bovinos, Uberlândia-MG, p.159-166.

Freitas, A.F., Teixeira, N.M. \& Durães, M.C. 1997. Período de serviço e sua influência sobre a produção de leite de vacas mestiças Europeu-Zebu. RevistaBrasileiraZootecnia, 26, 1103-1108.

Funston, R.N., Larson, D.M. \& Vonnahme, K.A. 2010. Effects of maternal nutrition on conceptus growth and offspring performance: Implications for beef cattle production. Journal Animal Science, 88, 205-215.

Gasser, C.L., Grum, D.E., Mussard, M.L., Fluharty, F.L., Kinder, J.E. \& Day, M.L. Induction of precocious puberty in heifers I: enhanced secretion of luteinizing hormone. Journal Animal Science, 84, 2035-2041.

Gasser, C.L., Burke, C.R., Mussard, M.L., Behlke, E.J., Grum, D.E., Kinder, J.E. \& Day, M.L. 2006b. Induction of precocious puberty in heifers II: advanced ovarian follicular development. Journal Animal Science, 84, 2042-2049.

Gasser, C.L., Bridges, G.A., Mussard, M.L., Grum, D.E., Kinder, J.E. \& Day, M.L. 2006c. Induction of precocious puberty in heifers III: hastened of estradiol negative feedback on secretion of luteinizing hormone. Journal Animal Science, 84, 2050-2056.

Gasser, C.L., Behlke, E.J., Grum, D.E. \& Day, M.L. 2006d. Effect of feeding highconcentrate diet on growth and attainment of puberty in early-weaned heifers. Journal Animal Science, 84, 3118-3122.

Guardieiro, M.M., Bastos, M.R., Mourão, G.B., Carrijo, L.H.D., Melo, E.O., Rumpf, R. \& Sartori, R. 2010. Função ovariana de novilhas Nelore alimentadas com dieta suplementada com gordura protegida ruminal. Revista Pesquisa Agropecuária Brasileira,45, 408414.

Hess, B.W. 2008. Impacto da nutrição materna no desempenho do bezerro. In: Anais do XII curso novos enfoques na produção $e$ reprodução de bovinos, Uberlândia-MG, p.215.

Hess, B.W., Lake, S.L., Scholljegerdes, E.J., Weston, T.R., Nayigihugu, V., Molle, J.D.C. \& Moss, G.E. 2005. Nutricional controls of beef cow reproduction. Journal Animal Science, 83:90-106.

Leandro, C.G., Amorim, M.F., Hirabara, S.M., Curi, R. \& Castro, R.M. 2009. Pode a atividade física materna modular a programação fetal induzida pela nutição? Revista de Nutrição, 22, 559-569.

Leroy, J.L.M.R., Vanholder, T., Van Knegsel, A.T.M., Garcia-Ispierto, I. \& Bols, P.E.J. 2009. Priorização de nutrientes em vacas leiteiras no pós-parto imediato: discrepância entre metabolismo e fertilidade? In: Anais do $X V$ curso novos enfoques na produção $e$ reprodução de bovinos, Uberlândia-MG, p.316.

Maggioni, D., Rotta, P.P., Marques, J.D.A., Zawadzki, F., Prado, R.M.D.P., Prado, I.N.D. 2008. Influência da proteína sobre a reprodução animal: uma revisão. Revista Campo Digital, 1(2)105-110.

Maquivar, M. \& Day, M.L. 2009. Regulação nutricional da puberdade. In: Anais do XIII curso novos enfoques na produção $e$ reprodução de bovinos, Uberlândia-MG, p.143-158.

Martin, J.L., Vonnahme, K.A., Adams, D.C., Lardy, G.P. \& Funston, R.N. 2007. Effects of dam nutrition on growth and reproductive 
performance of heifer calvez.Journal Animal Science, 85:841-847.

Mexia, A.A., Macedo, F.A.F., Macedo, R.M.G., Sakaguti, E.S., Santello, G.A., Capovilla, L.C.T., Zundt, M. \& Sasa, A. 2006. Desempenho e características das fibras musculares esqueléticas de cordeiros nascidos de ovelhas que receberam suplementação alimentar em diferentes períodos da gestação. Revista Brasileira de Zootecnia, 35(4):17801787.

Moore, J.E., Kunkle, W.E. \& Brown, W.F. 1991. Forage quality and the need for protein and energy supplements. In: 40th Annual Florida Beef Cattle Short Course Proceedings, Flórida, p.113-123.

Oliveira, R.L., Barbosa, M.A.A.F., Ladeira, M.M., Silva, M.M.P. \& Ziviani, A.C., 2006. Nutrição e manejo de bovinos de corte na fase de cria. In: Anais do II SIMBOI-Simpósio sobre desafios e novas tecnologias na bovinocultura de corte, Brasília, 54p.

Pate, F.M., Brown, W.F. \& Hammond, A.C. 1995. Value of feather meal in a molassesbased liquid supplement fed to yearling cattle consuming a forage diet. Journal Animal Science, 73, 2865-2872.

Paulino, P.V.R., Fonseca, M.A., Henriques, L.T., Valadares Filho, S.C. \& Detmann, E. 2010. Exigências nutricionais de vacas e bezerros Nelore. capítulo 8. BR Corte - Exigências Nutricionais de Zebuínos Puros e Cruzados, $2^{\circ}$ edição, 193p.

Pilau, A., Rocha, M.G., Restle, J., Silva, J.H.S., Freitas, F.K. \& Macari,S. 2005. Desenvolvimento de novilhas de corte recebendo ou não suplementação energética em pastagens com diferentes disponibilidades de forragem. Revista Brasileira de Zootecnia, 34, 1483-1492.

Pires, A.V., Biehl, M.V., Susin, I., Cruppe, L.H., Nepomuceno, D.D., Rocha, F.M. \& Ferreira, E.M. 2011. Interrelações entre nutrição e reprodução: fatores que potencializam o desempenho reprodutivo. In: Anais do I SIMBOV MT-Simpósio Mato-grossense de Bovinocultura de Corte, Cuiabá, cap.10, p.263-292.

Parra, B.C \& Beltran, M.P. 2008. Interação entre nutrição e reprodução em vacas de corte.
Revista Científica Eletrônica de Medicina Veterinária, VI, 11.

Potter, L., Lobato, J.F.P. \& Mielitz Netto, C.G.A. 2000. Análises econômicas de modelos de produção com novilhas de corte primíparas aos dois, três e quatro anos de idade. Revista Brasileira de Zootecnia,29, 861-870.

Rocha, M.G. \& Lobato, J.F.P. 2002. Sistemas de alimentação pós-desmama de bezerras de corte para acasalamento com 14/15 meses de idade. Revista Brasileira de Zootecnia, 31, 1814-1822.

Sá Filho, M.F., Gimenes, L.U., Sales, J.N.S., Crepaldi, G.A., Medalha, A.G. \& Baruselli, P.S. 2008. IATF em novilhas In: Anais do $3^{\circ}$ SIRAA- Simpósio Internacional de Reprodução Animal Aplicada, Londrina-PR, cap.7, p.54-67.

Santello, G.A., Macedo, F.A.F., Macedo, R.M.G., Martins, E.N., Lourenço, F.J. \& Dias, F.J. 2010. Características das fibras musculares de cordeiros nascidos de ovelhas recebendo suplementação protéica no terço inicial da gestação. Revista Brasileira de Zootecnia, 39, 2288-2296.

Santos, D.T., Rocha, M.G., Genro, T.C.M., Quadros, F.L.F., Freitas, F.K., Roman, J; \& Neves, F.P. 2004. Suplementos energéticos para recria de novilhas de corte em pastagens anuais. Análise econômica. Revista Brasileira de Zootecnia, 33, 2359-2368.

Santos, D.T., Rocha, M.G., Quadros, F.L.F., Genro, T.C.M., Montagner, D.P., Gonçalves, E.N., Roman, J. 2005. Suplementos energéticos para recria de novilhas de corte em pastagens anuais. Desempenho animal. Revista Brasileira de Zootecnia, 34, 209-219.

Santos, J.E.P. \& Sá Filho, M.F. 2006. Biotecnologia da reprodução em bovinos. In: Anais do $2^{\circ}$ Simpósio Internacional de Reprodução Animal Aplicada. São Paulo. p.30-54.

Sartori, R. \& Mollo, M.R. 2007. Influência da ingestão alimentar na fisiologia reprodutiva da fêmea bovina. Revista Brasileira de Reprodução Animal, 31, 197-204.

Silva, M.D., Barcellos, J.O.J. \& Prates, E.R. 2005. Desempenho reprodutivo de novilhas de corte acasaladas aos 18 ou aos 24 meses de 
idade. Revista Brasileira de Zootecnia,34, 2057-2063.

Squires, E.J. 2003. Aplied Animal Endocrinology, CabiPublishing, $1^{\circ}$ edição, p.312.

Stalker, L.A., Adams, D.C., Klopfenstein, T.J., Feus, D.M. \& Funston, R.N. 2006. Effects of pré - and postpartum nutrition on reproduction in spring calving cows and calf feedlot permorfance. Journal Animal Science, $84,2582-2589$.

Tong, J., Zhu, M.J., Underwood, K.R., Hess, B.W., Ford, S.P. \& Du, M. 2008. Ampactivated protein kinase and adipogenesis in sheep fetal muscle and 3T3-L1 cells. Journal Animal Science, 86, 1296-1305.

Underwood, K.R., Tong, J.F., Kimzey, J.M., Price, P.L., Grings, E.E., Hess, B.W., Means, W.J. \& Du, M. 2008. Gestational nutrition affects growth and adipose tissue deposition in steers. Proceedings, Western Section, American Society of Animal Science, 59, 2932.

Vaz, R.Z. \& Lobato, J.F.P. 2010. Efeito da idade do desmame no desenvolvimento de novilhas de corte até os 14/15 meses de idade. RevistaBrasileira de Zootecnia, 39, 289-298.

Webb, R., Garnswothy, P.C., Gong, J.C. \& Armstrong, D.G. 2004. Control of follicular growth: Local interactions and nutritional influences. Journal Animal Science, 82, 63-74.

Wu, G., Bazer, F.W., Wallace, J.M. \& Spencer, T.E. 2006. Board-Invited Review: Intruterine growth retardaton: Implications for the animal sciences. Journal Animal Science, 84, 23162337.

Zanine, A.M., Souza, A.L., Sousa, B.M.L., Ferreira, D.J., Negrão, F.M. \& Bonelli, E.A. 2011. Manejo de gramíneas tropicais sob pastejo intensivo. In: Anais do I SIMBOV MTSimpósio Mato-grossense de Bovinocultura de Corte, Cuiabá, cap.03 p.75-96.

Zhu, M.J., Ford, S.P., Nathanielsz, P.W. \& Du, M. 2004. Effect of maternal nutrient restriction in sheep on the development of fetal skeletal muscle. Biology of Reproduction, 71, 1968-1973.

Recebido em Julho 22, 2014

Aceito em Setembro 23, 2014

License information: This is an open-access article distributed under the terms of the Creative Commons Attribution License, which permits unrestricted use, distribution, and reproduction in any medium, provided the original work is properly cited. 